\title{
PÓLIPO FIBROEPITELIAL DE URETRA EN UN ADULTO
}

\author{
J.M. LANZAS PRIETO, C.L. MENÉNDEZ FERNÁNDEZ*, F.J. PÉREZ GARCÍA, \\ R. GUTIÉRREZ GARCÍA, J. GONZÁLEZ TUERO, J.L. GUATE ORTIZ
}

Departamentos de Urología. *Anatomía Patológica. Hospital San Agustín de Avilés. Asturias.

Actas Urol Esp. 27 (8): 654-656, 2003

\section{RESUMEN}

PÓLIPO FIBROEPITELIAL DE URETRA EN UN ADULTO

Presentamos el caso de un pólipo fibroepitelial de uretra prostática en un paciente de cuarenta y cinco años. Este tipo de pólipos son poco frecuentes en el adulto. Los síntomas principales que manifestaba el paciente eran hematuria y disminución ocasional del chorro miccional. Mostramos las imágenes endoscópicas del tumor, así como detalles de su histología que corresponde a una lesión polipoide con un revestimiento urotelial típico sobre tejido conectivo laxo, con algún fascículo de músculo liso sin estructuras glanduliformes de tipo prostático ni componente inflamatorio apreciable.

PALABRAS CLAVE: Pólipos. Uretra.

\section{ABSTRACT}

\section{FIBROEPITHELIAL URETHRAL POLYP IN AN ADULT}

We present the case of a fibroepithelial polyp of the prostatic urethra in a forty-five year old patient. This type of polyp is rare in the adult. The principal symptoms which the patient presented were haematuria and an intermittent reduction in micturitional flow. Endoscopic images of the tumour are shown and certain details of its histology; this is a polypoid lesion of loose connective tissue covered by typical urothelium, with occasional fascicles of smooth muscle, no prostatic-type glandular structures and no appreciable inflammatory component.

KEY WORDS: Polyps. Urethra.

$\mathrm{L}$ os pólipos de uretra posterior son lesiones exofíticas benignas poco frecuentes. El primer caso descrito en la literatura se debe a Henry Thompson en 1885, que lo describió en una autopsia ${ }^{1}$.

El pólipo fibroepitelial es una de las entidades histopatológicas que componen este grupo de lesiones. Puede localizarse en cualquier punto del tracto urinario, aunque la localización más frecuente es en la unión ureteropiélica y en el verum montanum.

Los pólipos fibroepiteliales de uretra se observan con más frecuencia en la primera década de la vida ${ }^{2}$. Hasta 1998 sólo se han descrito diez casos de adultos en la literatura ${ }^{3}$. Gunter y cols. (1979) destacaron que la característica histopatológica discriminatoria de los pólipos fibroepiteliales de uretra es la ausencia de estructuras glandulares prostáticas ${ }^{4}$.

\section{CASO CLÍNICO}

Paciente varón de cuarenta y cinco años, que consultó por cuadro de varios episodios de hematuria macroscópica sobre todo al final de la micción, y chorro miccional débil en ocasiones. La exploración física fue normal. 
La analítica fue normal, incluyendo un sedimento y tres citologías de orina.

Se realizó una UIV que también fue normal.

Se le efectuó una uretrocistoscopia que mostró una lesión polipoidea alargada, con un tallo estrecho que se originaba en la pared posterior de la uretra prostática, adyacente y en contacto con el utrículo prostático y se extendía a lo largo de la uretra prostática, flotando sin adherirse a ella (Fig. 1a). Este tallo en su tercio distal se ensanchaba y en ocasiones se deslizaba a través del cuello vesical al interior de la vejiga (Fig. 1b). La vejiga era normal.

Se le realizó una resección transuretral de la lesión quedando el paciente asintomático.

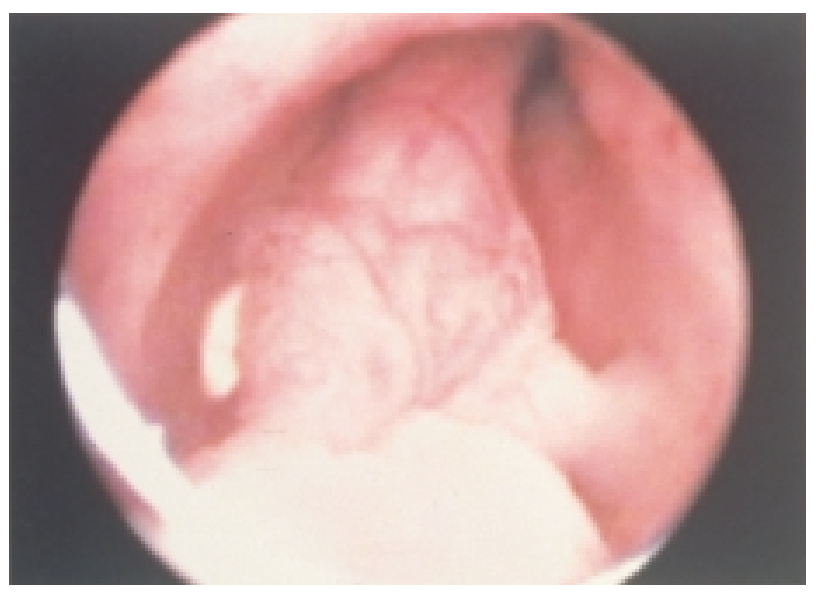

FIGURA 1a: Lesión polipoide que se inicia en la uretra prostática junto al verum montanum.

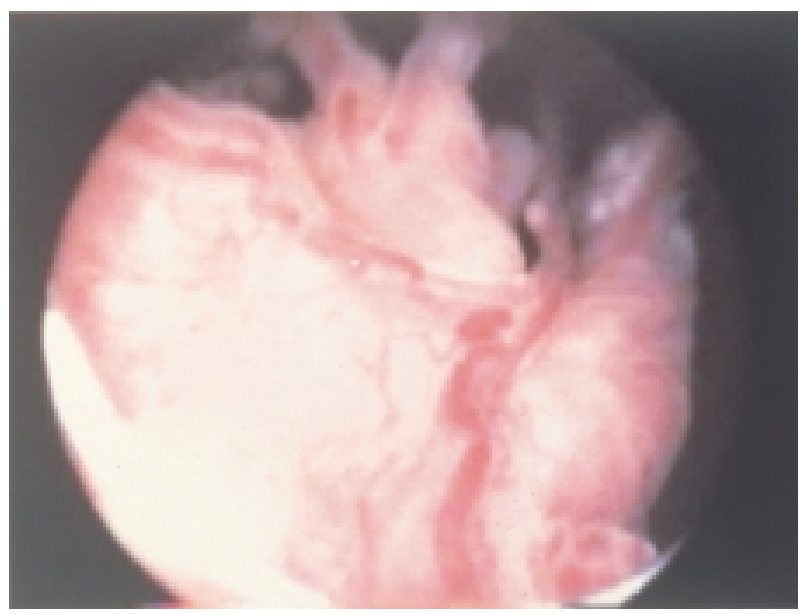

FIGURA 1b. Porción distal del pólipo que se encuentra "flotando" en el cuello vesical.
La lesión polipoide, de $1,5 \mathrm{~cm}$ de diámetro máximo, histológicamente mostraba un revestimiento transicional típico sobre un tejido conectivo laxo, con vasos congestivos (Fig. 2), algún fascículo de músculo liso (Fig. 3), sin estructuras acinares de tipo prostático (expresión negativa para PSA y PAP) y sin componente inflamatorio destacable.

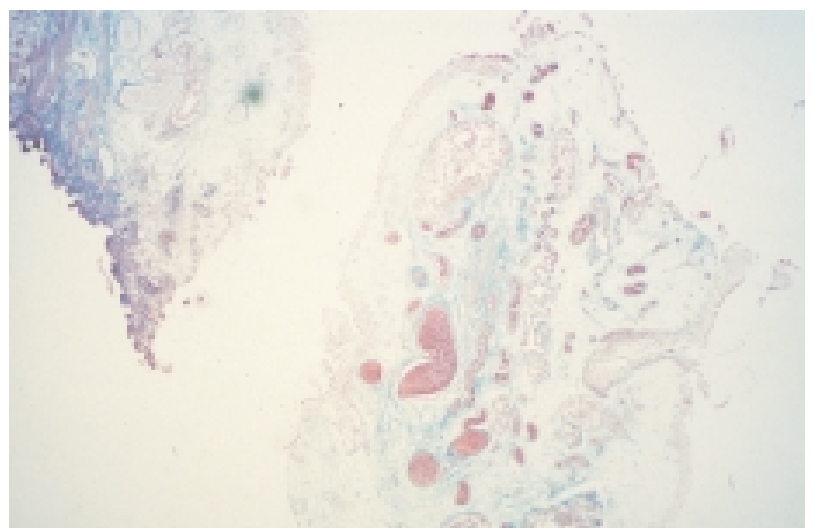

FIGURA 2. Lesión polipoide uretral con revestimiento epitelial transicional (Tinción de Masson $x$ 20).

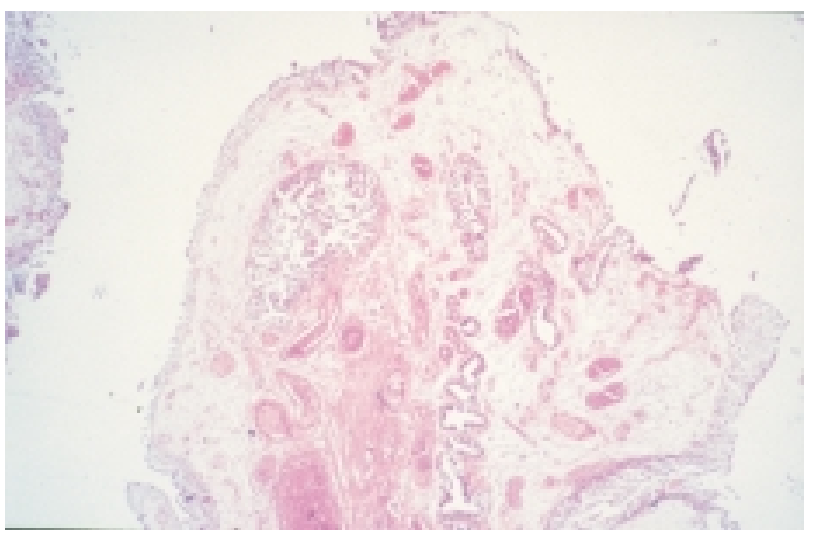

FIGURA 3. Pólipo fibroepitelial de uretra donde se observa un estroma laxo, alguna invaginación del urotelio y fibras de músculo liso en la porción central (HE $x 40$ ).

\section{DISCUSIÓN}

Los pólipos fibroepiteliales de uretra son lesiones tumorales benignas que se localizan preferentemente en contacto con el verum montanum y se diagnostican mayoritariamente en la infancia ${ }^{5}$. Kunimi y cols. ${ }^{6}$ trataron de clasificar las lesiones papilares o polipoides de la uretra prostática en cuatro grupos. El primero es considerado como hamartomas, está caracterizado por la presencia 
de elementos epiteliales característicos de la glándula prostática (con positividad para PAS, PAP y PSA), posibilidad de recurrencia y en algún caso con un comportamiento potencialmente neoplásico. A este grupo pertenecerían los pólipos vellosos, el tejido prostático ectópico de uretra, la carúncula uretral, la metaplasia adenomatoide de uretra prostática, los pólipos adenomatosos, los pólipos epiteliales (benignos), los pólipos uretrales prostáticos, el adenoma papilar y la hiperplasia epitelial prostática papilar. El segundo grupo se diferencia del anterior por la ausencia de estructuras glandulares prostáticas y se denominan pólipos fibroepiteliales. El tercer grupo tiene un origen inflamatorio $\mathrm{y}$ ha sido denominado uretritis polipoide o uretritis papilar proliferativa. El cuarto grupo es el pólipo uretral de la infancia y la histopatología es similar al segundo grupo.

La histogénesis del pólipo fibroepitelial congénito de la uretra que se diagnostica en la edad adulta sería la misma que la del diagnosticado en la edad infantil, es decir tumores congénitos benignos de uretra que representarían proyecciones de las capas de la pared en la luz uretral ${ }^{2}$.

La histopatología de estos pólipos se caracteriza por un tallo fibrovascular compuesto de tejido conjuntivo fibrovascular y fibras de músculo liso, sin estructuras glandulares prostáticas y que está revestido de un epitelio transicional que puede mostrar áreas de metaplasia escamosa ${ }^{4}$.

La manifestación clínica que presentan con más frecuencia el grupo de edad adulta es la hematuria ${ }^{7,8}$. Los sintomas miccionales obstructivos son más frecuentes en la infancia ${ }^{2,5}$.

El diagnóstico se establece mediante la cistouretrografía miccional (defecto de repleción en la uretra prostática), la ecografía (lesión polipodea que protuye desde el cuello vesical en la base de la vejiga) ${ }^{9}$ o mediante la visualización directa por uretrocistoscopia.
El tratamiento del pólipo fibroepitelial en el adulto es la resección por vía transuretral, a diferencia del pólipo fibroepitelial infantil que generalmente se aborda por vía suprapúbica ${ }^{5}$.

El pronóstico tras la resección de estos pólipos en el adulto es excelente. No hemos encontrado ningún caso de reciciva en este grupo de pacientes.

Por lo tanto, presentamos el caso de un pólipo fibroepitelial de uretra, que es poco frecuente observarlo en los adultos, comentando los aspectos clínicos, diagnósticos y terapéuticos.

\section{REFERENCIAS}

1. THOMPSON H.: Structure of the urethra. Transactions of the Pathological Society of London 1856; 7: 250.

2. DOWNS RA.: Congenital polyps of the prostatic urethra: a review of the literature and report of two cases. Br J Urol 1970; 42: 76-85.

3. MATTEI FM, GIOVANNELLI V, DEL VECCHIO MT, MINACCI C.: Congenital fibroepithelial polyp of prostatic urethra in an adult. Arch It Urol 1998; 70: 173175.

4. GUNTER I, ABRAMS HJ, SUTTON AP, BUCHBINDER MI.: Fibroepithelial polyp of the verumontanum: a case report and review of the literature. $J$ Urol 1979; 121: 525-526.

5. FOSTER RS, GARRET RA.: Congenital posterior urethral polyps. J Urol 1998; 136: 670-672.

6. KUNIMI K, SHIMAMURA M, MIYAGI T, KURUMAYA H.: Fibroepithelial polyp of the verumontanum. Int Urol \& Nephrol 1994; 26 (6): 669-672.

7. HUTCHINSON I, McGEORGE A, GARLAND I et al.: Congenital urethral polyp in an adult. $\mathrm{Br} J$ Urol 1983; 55: 576-677.

8. MIROGLU C, ILHAN A, OZDILER E.: Congenital urethral polyp in an adult. Br J Urol 1988; 61: 531-532.

9. BARZILAI M, SHINAWI M, ISH-SHALOM N, MECZ Y, PELED N, LURIE A.: A fibroepithelial urethral polyp protuding into the base of the bladder: sonographic diagnosis. Urol Int 1996; 57: 129-131.

Dr. J.M. Lanzas Prieto

Servicio de Urología. Hospital San Agustín 33400 Avilés (Asturias)

(Trabajo recibido el 4 septiembre de 2002) 